\title{
Detection of extended-spectrum beta-lactamase genes among Escherichia coli isolates from urinary tract infection in Mashhad
}

\author{
Maryam Hafiz', Gholamreza Hashemi Tabar ${ }^{1, *}$, Mehrnaz $\operatorname{Rad}^{1}$ \\ ${ }^{1}$ Department of Pathobiology, School of Veterinary Medicine, Ferdowsi University of Mashhad, Mashhad, Iran
}

\begin{abstract}
Urinary tract infections (UTIs) are known as one of the most important infections around the world, and Escherichia coli is the most important cause of UTI. Also, the empiric treatment and misusing of antimicrobial agents has led to increasing multi-drug resistance around the world which is a worldwide concern. Extended-spectrum beta-lactamase (ESBLs) is an enzyme group that is produced by the Enterobacteriaceae family. The three main ESBLs enzyme are as follow: bla $\mathrm{CTX}-\mathrm{M}$, bla $a_{\mathrm{TEM}}$, and bla $\mathrm{SHV}$, additionally, there are several types of each of them by the same mechanism. This study was conducted to evaluate the prevalence of ESBL genes among $E$. coli isolated from UTI patients. A total of 105 isolates were collected from UTI patients at two hospitals in Mashhad from 2017 to 2019. Bacterial identification was performed by standard microbiologic methods. The assessment of antimicrobial susceptibility was accomplished by the disk diffusion method. The presence of ESBL genes was investigated by multiplex-PCR. The prevalence of UTI, among females, was identified more than males. Furthermore, the bla тем and blacтх-м genes were detected in all isolates, but only six isolates (5.7\%) were harboring blashv. The considerable role of $E$. coli in UTI infection, as well as the presence of ESBL genes in $E$. coli strains, emphasize the need for surveillance of antimicrobial therapy to prevent the extension of resistance among clinical strains.
\end{abstract}

Keywords: Escherichia coli, ESBL, Urinary tract infection, Multiplex-PCR

\section{Introduction}

Urinary tract infections (UTIs) happen through community-acquired or nosocomial-acquired, which are one of the most prevalent types of human infection $[1,2]$. Escherichia coli is known as the most important pathogen in UTIs, among both outpatient and inpatient $[3,4]$. On the other hand, the empiric of treatment and misusing of antimicrobial agents such as, beta-lactams, beta-lactamase inhibitor, fluoroquinolones, and carbapenems, has led to increasing multi-drug resistance around the world which is a worldwide concern [5, 6]. Extendedspectrum beta-lactamase (ESBLs) is an enzyme group

\section{*Corresponding author:}

Gholamreza Hashemi Tabar, Ph.D

Azadi Square, Mashhad, Razavi Khorasan Province, Iran,

P.O. Box: 9177948974

Tel/Fax: +98 5138836056

Email: hashemit@um.ac.ir

https://orcid.org/oooo-0001-9760-1096

Received: June, 14, 2021

Accepted: July, 12, 2021 that is produced by the Enterobacteriaceae family, which are mostly isolated from inpatient cases [7]. The ESBL positive bacteria are able to inactivate several antimicrobial agents including an oxyimino-group such as cephalosporins (e.g. ceftazidime, and ceftriaxone), monobactam (e.g. aztreonam), but not able to inactivate cephamycin, and carbapenems [7, 8]. The three main ESBL enzymes are bla CTX-M, $_{\text {bla }}$ TEM, and blasHv $[9,10]$. These enzymes are encoded generally by genes located on plasmids. Actually, the mutation in these genes (particularly bla TEM and blasHv) led to the change in the form of the enzyme near its active site to increment the affinity and

(C) The Author(s) 2021
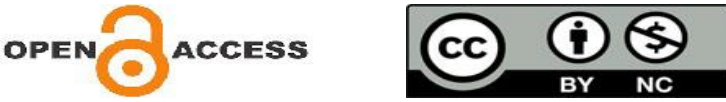
hydrolytic capability of beta-lactamase for oxyimino compounds [11]. Also, some of them are encoding on transposons which could transmit between organisms [8]. The growing up of ESBL producing strains brings up some problems including the transmission of resistance to other organisms, refusing treatment, and increase in mortality rate. So, more surveillance is needed to identify the rate of the problem and help to select appropriate antimicrobial agents to treat the infection. This study was conducted to evaluate the prevalence of bla тем, bla Стх-м, and blasHv genes by multiplex polymerase chain reaction (M-PCR) among E. coli isolated from UTI patients. agar (TSI), and Methyl Red-Voges Proskauer test (MR-VP) has been studied.

\subsection{Antimicrobial susceptibility test}

The assessment of antimicrobial susceptibility was accomplished by the disk diffusion method recommended by the Clinical and Laboratory Standards Institute (CLSI, 2020) (13)[12], against 15 antibiotic disks (Padtanteb, Iran) as follow: ceftazidime (30 $\mu \mathrm{g})$, imipenem (10 $\mu \mathrm{g})$, amikacin (30 $\mu \mathrm{g})$, nalidixic acid (30 $\mu \mathrm{g})$, ampicillin (10 $\mu \mathrm{g})$, ciprofloxacin $(5 \mu \mathrm{g})$, cefixime $(5 \mu \mathrm{g})$, cefazoline $(30 \mu \mathrm{g})$, ceftriaxone $(30 \mu \mathrm{g})$, meropenem $(10 \mu \mathrm{g})$, gentamicin

Table 1. The information of oligonucleotides used as primer in multiplex-PCR

\begin{tabular}{|c|c|c|c|}
\hline Primer name & Primer sequence (5'-3') & Amplicon size (bp) & Reference \\
\hline blaTEM164.SE & TCG CCG CAT ACA CTA TTC TCA GAA TGA & \multirow{2}{*}{445} & \multirow{6}{*}{14} \\
\hline blaTEM164.AS & ACG CTC ACC GGC TCC AGA TTT AT & & \\
\hline blaSHV.SE & ATG CGT TAT ATT CGC CTG TG & \multirow{2}{*}{724} & \\
\hline blaSHV.AS & TGC TTT GTT ATT CGG GCC AA & & \\
\hline blaCTX-M. U1 & ATG TGC AGC ACC AGT AAA GTG ATG GC & \multirow{2}{*}{593} & \\
\hline blaCTX-M. U2 & TGG GTA AAG TAA GTG ACC AGA ATC AGC GG & & \\
\hline
\end{tabular}

Table 2. The frequency of UTI in different age groups

\begin{tabular}{lccccccc}
\hline Age groups & $<\mathbf{1 0}$ & $\mathbf{1 1 - 2 0}$ & $\mathbf{2 1 - 3 0}$ & $\mathbf{3 1 - 4 0}$ & $\mathbf{4 1 - 5 0}$ & $\mathbf{5 1 - 6 0}$ & $>\mathbf{6 0}$ \\
\hline Female & 8 & 3 & 9 & 5 & 5 & 10 & 16 \\
\hline Male & 5 & 0 & 2 & 3 & 6 & 5 & 28 \\
\hline Total ${ }^{\text {a }}$ & 13 & 3 & 11 & 8 & 11 & 15 & 44 \\
\hline & \multicolumn{8}{c}{} \\
& ${ }^{\text {a }}$ Results presented as number of cases
\end{tabular}

\section{Materials and Methods}

2.1 Sample's collection

A total of $105 \mathrm{E}$. coli isolates were collected from UTI patients at Ghaem and Emamreza hospitals in Mashhad from 2017 to 2019. Also, the basic information of patients was gathered, including age and gender, UTI history, hospital visit reports, and reports of taken antimicrobial agents from patients. Isolates cultured on selective-differential media, MacConkey agar (MAC), and Eosin Methylene Blue agar (EMB), were incubated overnight at $37^{\circ} \mathrm{C}$. Then, microscopically examination was done by Gram staining from lactose-positive colonies. Likewise, biochemical profiling, such as Oxidase/Catalase activity, Motility, Indole, Urease, Triple Sugar Iron
(10 $\mu \mathrm{g})$, nitrofurantoin (300 $\mu \mathrm{g})$, cefepime (30 $\mu \mathrm{g})$, cefotaxime $(30 \mu \mathrm{g})$ and co-trimoxazole (1.25/23.75 $\mu \mathrm{g})$. E. coli ATCC 25922 was used as a positive control for antimicrobial susceptibility tests.

\subsection{PCR amplification}

DNA extraction was done by the boiling method as described earlier by Nazari et al. [13]. The prepared DNA samples were assessed for prevalence of blaTEM, blasHv, and blactx-m genes by M-PCR by using the MJ mini thermal cycler (Bio-Rad, Hercules, CA, USA) [14]. The PCR reaction was conducted in 25 volumes including $12.5 \mu \mathrm{l}$ of PCR 2X MasterMix (Parstous company, Iran) containing Taq DNA Polymerase, reaction buffer, dNTPs mixture, a protein stabilizer, and the convenience for use was optimized by adding 
sediment for electrophoresis and $2 \mathrm{x}$ solution of loading dye, $1 \mu \mathrm{l}$ of each primer (10 pM), $2 \mu \mathrm{l}$ of DNA template (100 ng/reaction) and $4.5 \mu \mathrm{l}$ of Nuclease-free water. PCR conditions were as follow: initial denaturation at $95^{\circ} \mathrm{C}$ for 15 seconds; followed by 35 cycles of denaturation at $94^{\circ} \mathrm{C}$ for 30 seconds, annealing at $61^{\circ} \mathrm{C}$ for 40 seconds, and extension at $72^{\circ} \mathrm{C}$ for 2 minutes with a final extension at $72^{\circ} \mathrm{C}$ for 10 minutes [15]. Electrophoresis of amplicons was performed using $1.5 \%$ agarose gels. The primers' information is listed in Table 1. Also, E. coli ATCC 35218 and distilled water were used as the positive and negative control, respectively.

\section{Results}

3.1 Prevalence of UTI in different ages and genders

Based on the results, it was determined that the prevalence of UTI among females with 56 (53.3\%) cases was more than males with 49 (46.7\%) cases. Most isolates were recovered from patients with $>60$ ages, and the lowest rate was observed in 11-20 age groups. The information of patients' age groups was listed in Table 2.

\subsection{Antimicrobial susceptibility test}

According to the results, amikacin (98\%), meropenem (93\%), nitrofurantoin (89\%), and imipenem (88\%) revealed the highest activity against isolates, respectively. All results are listed in Table 3.

\subsection{PCR results}

The analysis of PCR products on gel electrophoresis revealed that the most prevalent ESBLs among studied isolates were bla $a_{\mathrm{TEM}}$, and bla $a_{\mathrm{CTX}}$ м genes (100\%). While only six (5.71\%) isolates were carried the blashv gene.

\section{Discussion}

UTI is known as one of the most highlighted healthcare infections. Our finding notes that women have a higher rate of UTI than men. This fact confirms earlier findings of the stress UTI in females [16-19]. Also, the most prevalent was observed in the $>60$ age group, which was similar to previous surveys [20, 21]. However, this result was in contrast with other observations, which reported the highest prevalence in 2-10 and 20-29 age groups, respectively [17, 22]. Our results revealed the highest resistance rate for

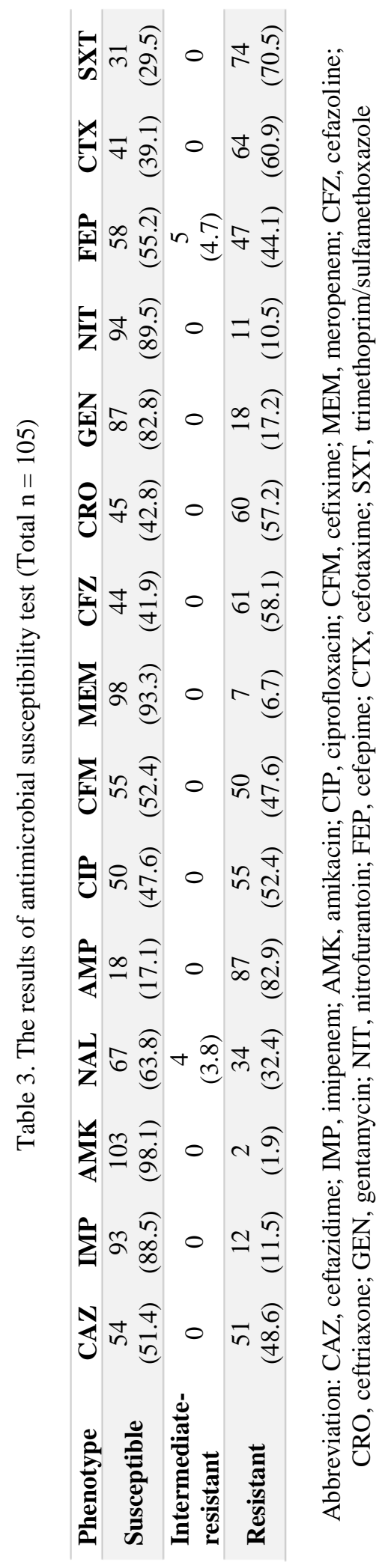


ampicillin (82.8\%) and cotrimoxazole (70.4\%) which was consistent whit previous surveys [17, 23-25]. However, another study was recorded a lower resistance rate for ampicillin and cotrimoxazole, $67 \%$ and $45 \%$, respectively [26]. On the other hand, the highest susceptibility was observed against amikacin, meropenem, nitrofurantoin, and imipenem. While the lower susceptibility for amikacin (61\%) and nitrofurantoin (72\%) has been reported in an earlier survey [27]. However, our finding for nitrofurantoin susceptibility was close to other studies $[17,28]$. Also, the susceptibility rate of isolates to imipenem and amikacin in the current study was in line with previous surveys $[17,23,29]$.

According to earlier reports, the high rate of ESBL$E$. coli was noted from UTI among both inpatient and outpatient, whereas it was more significant among inpatient $[24,30]$.

Generally, the highest presence of ESBLs was recorded for bla with earlier results [9, 31-34]. Although, some studies reported a lower rate of blactх-м, $28 \%$, and $32 \%$, respectively $[35,36]$. This discrepancy can be explained by different geography and the increase of genes transferring during the time. On the other hand, blasHV was detected in only six isolates. Our experiment about the prevalence of the blasHV gene was close to previous survey [33]. According to these results, the blasHv gene is not predominant as the two other genes. However, new studies revealed a high frequency of blasHv that might increase in the future $[11,37]$. Certainly, further tests such as confirmatory ESBL test and statistical analysis are required to determine the relationship between these genes and resistant phenotype.

The considerable role of $E$. coli in UTI infection, as well as the presence of ESBL genes in $E$. coli strains, emphasize the need for surveillance of antimicrobial therapy to prevent the extension of resistance among clinical strains.

\section{Acknowledgments}

The authors would like to thank all Ghaem and Imam Reza hospitals staff, which collaborating in collecting isolates.

\section{Author contributions}

All authors contributed equally to each part of the manuscript and approved the final version.

\section{Conflict of interests}

The authors claim that there is no conflict of interest.

\section{Ethical declarations}

This study was in accordance with the declaration of Helsinki and ethical permission was sought from the institutional Ethics Committee of Ferdowsi University of Mashhad, Mashhad, Iran. However, because we only used leftovers from clinical specimens, the local ethics committee waived the need for informed consent.

\section{Financial Support}

This study was funded by Ferdowsi University of Mashhad, Mashhad, Iran (Grant number 109).

\section{References}

1. Sedighimehr N, Dehghan Manshadi F. Electrical Stimulation for Lower Urinary Tract Dysfunction in People with Multiple Sclerosis: A Systematic Review. J Clin Physiother Res. 2018; 3(2):48-53.

2. Haghighatpanah M, Mojtahedi A. Characterization of antibiotic resistance and virulence factors of Escherichia coli strains isolated from Iranian inpatients with urinary tract infections. Infect Drug Resist. 2019; 12:2747-54.

3. Larramendy S, Gaultier A, Fournier JP, Caillon J, Moret L, Beaudeau F. Local characteristics associated with higher prevalence of ESBL-producing Escherichia coli in communityacquired urinary tract infections: an observational, cross-sectional study. J Antimicrob Chemother. 2021; 76(3):789-95.

4. Fathi J, Ebrahimi F, Nazarian S, Hajizade A, Malekzadegan Y, Abdi A. Production of egg yolk antibody (IgY) against shiga-like toxin (stx) and evaluation of its prophylaxis potency in mice. Microb Pathog. 2020; 145:104199.

5. Uzodi AS, Lohse CM, Banerjee R. Risk Factors For and Outcomes of Multidrug-Resistant Escherichia coli Infections in Children. Infect Dis Ther. 2017; 6(2):245-57.

6. Rawat D, Nair D. Extended-spectrum $\beta$-lactamases in Gram Negative Bacteria. J Glob Infect Dis. 2010; 2(3):263-74.

7. Abayneh M, Tesfaw G, Abdissa A. Isolation of ExtendedSpectrum $\beta$-lactamase- (ESBL-) Producing Escherichia coli and Klebsiella pneumoniae from Patients with Community-Onset Urinary Tract Infections in Jimma University Specialized Hospital, Southwest Ethiopia. Can J Infect Dis Med Microbiol. 2018; 2018:4846159.

8. Shah AA, Ali Y, Maqbool A, Abbasi SA. Phenotypic detection of extended-spectrum beta-lactamase in multidrug-resistant acinetobacter baumannii isolated in Fauji Foundation Hospital Rawalpindi. J Pak Med Assoc. 2021; 71(4):1144-7.

9. Manyahi J, Moyo SJ, Tellevik MG, Ndugulile F, Urassa W, Blomberg B, et al. Detection of CTX-M-15 beta-lactamases in Enterobacteriaceae causing hospital- and community-acquired 
urinary tract infections as early as 2004, in Dar es Salaam, Tanzania. BMC Infect Dis. 2017; 17(1):282.

10. Hashemi B, Afkhami H, Khaledi M, Kiani M, Bialvaei AZ, Fathi $\mathrm{J}$, et al. Frequency of Metalo beta Lactamase genes, bla IMP1, INT 1 in Acinetobacter baumanii isolated from burn patients North of Iran. Gene Rep. 2020; 21:100800.

11. Pishtiwan AH, Khadija KM. Prevalence of blaTEM, blaSHV, and blaCTX-M Genes among ESBL-Producing Klebsiella pneumoniae and Escherichia coli Isolated from Thalassemia Patients in Erbil, Iraq. Mediterr J Hematol Infect Dis. 2019; 11(1):e2019041.

12. CLSI. Performance Standards for Antimicrobial Susceptibility Testing. 3oth ed. CLSI Supplement M100. Wayne, PA: Clinical and Laboratory Standards Institute; 2020.

13. Nazari M, Youzbashi Z, Khaledi M, Fathi J, Afkhami H. Detection of carbapenem resistance and virulence genes among Acinetobacter baumannii isolated from hospital environments in center of Iran. J Curr Biomed Rep. 2021; 2(1):14.

14. van Driel AA, Notermans DW, Meima A, Mulder M, Donker GA, Stobberingh EE, et al. Antibiotic resistance of Escherichia coli isolated from uncomplicated UTI in general practice patients over a 10-year period. Eur J Clin Microbiol Infect Dis. 2019;38(11):21518.

15. Miraalami G, Parviz M, Khalajzadeh S. Evaluation of Antibiotic Resistance in Extended-spectrum Beta-lactamase (ESBL) Genes in the E. coli Isolates of Urinary Infections. J Babol Univ Med Sci. 2015; 17(8):19-26.

16. Haq I, Lal A, Ullah A, Ahmad A, Akram A, Siraj S. Frequency of urinary tract infection in children and their sensitivity pattern in swat. J Saidu Med Coll. 2017; 7(1):8-11.

17. Ramírez-Castillo FY, Moreno-Flores AC, Avelar-González FJ, Márquez-Díaz F, Harel J, Guerrero-Barrera AL. An evaluation of multidrug-resistant Escherichia coli isolates in urinary tract infections from Aguascalientes, Mexico: cross-sectional study. Ann Clin Microbiol Antimicrob. 2018; 17(1):34.

18. Hossain A, Hossain SA, Fatema AN, Wahab A, Alam MM, Islam $\mathrm{MN}$, et al. Age and gender-specific antibiotic resistance patterns among Bangladeshi patients with urinary tract infection caused by Escherichia coli. Heliyon. 2020; 6(6):e04161.

19. Fatima T, Rafiq S, Iqbal A, Husnain S. Prevalence and Antibiogram of MDR E. coli Strains Isolated from UTI Patients1-Year Retrospective Study at Nishtar Medical Hospital, Multan. SN Compr Clin Med. 2020; 2(4):423-31.

20. Lob SH, Nicolle LE, Hoban DJ, Kazmierczak KM, Badal RE, Sahm DF. Susceptibility patterns and ESBL rates of Escherichia coli from urinary tract infections in Canada and the United States, SMART 2010-2014. Diagn Microbiol Infect Dis. 2016; 85(4):45965.

21. Zubair KU, Shah AH, Fawwad A, Sabir R, Butt A. Frequency of urinary tract infection and antibiotic sensitivity of uropathogens in patients with diabetes. Pak J Med Sci. 2019; 35(6):1664-8.

22. Kulkarni SR, Peerapur BV, Sailesh KS. Isolation and Antibiotic Susceptibility Pattern of Escherichia coli from Urinary Tract Infections in a Tertiary Care Hospital of North Eastern Karnataka. J Nat Sci Biol Med. 2017; 8(2):176-80.

23. Parajuli NP, Maharjan P, Parajuli H, Joshi G, Paudel D, Sayami $\mathrm{S}$, et al. High rates of multidrug resistance among uropathogenic Escherichia coli in children and analyses of ESBL producers from Nepal. Antimicrob Resist Infect Control. 2017; 6:9.
24. Zorgani A, Almagatef A, Sufya N, Bashein A, Tubbal A. Detection of CTX-M-15 Among Uropathogenic Escherichia coli Isolated from Five Major Hospitals in Tripoli, Libya. Oman Med J. 2017; 32(4):322-7.

25. Alqasim A, Abu Jaffal A, Alyousef AA. Prevalence of Multidrug Resistance and Extended-Spectrum $\beta$-Lactamase Carriage of Clinical Uropathogenic Escherichia coli Isolates in Riyadh, Saudi Arabia. Int J Microbiol. 2018; 2018:3026851.

26. Yllmaz E, Aslantaş Ö. Phylogenetic Group/Subgroups Distributions, Virulence Factors, and Antimicrobial Susceptibility of Escherichia coli Strains from Urinary Tract Infections in Hatay. Rev Soc Bras Med Trop. 2020; 53:e20190429.

27. Patel HB, Soni ST, Bhagyalaxmi A, Patel NM. Causative agents of urinary tract infections and their antimicrobial susceptibility patterns at a referral center in Western India: An audit to help clinicians prevent antibiotic misuse. J Family Med Prim Care. 2019; 8(1):154-9.

28. Zilberberg MD, Nathanson BH, Sulham K, Shorr AF. Antimicrobial Susceptibility and Cross-Resistance Patterns among Common Complicated Urinary Tract Infections in U.S. Hospitals, 2013 to 2018. Antimicrob Agents Chemother. 2020; 64(8).

29. Fatima S, Muhammad IN, Usman S, Jamil S, Khan MN, Khan SI. Incidence of multidrug resistance and extended-spectrum betalactamase expression in community-acquired urinary tract infection among different age groups of patients. Indian $\mathrm{J}$ Pharmacol. 2018; 5O(2):69-74.

30. Al-Jamei SA, Albsoul AY, Bakri FG, Al-Bakri AG. Extendedspectrum $\beta$-lactamase producing $\mathrm{E}$. coli in urinary tract infections: A two-center, cross-sectional study of prevalence, genotypes and risk factors in Amman, Jordan. J Infect Public Health. 2019; 12(1):21-5.

31. Abe Y, Inan-Erdogan I, Fukuchi K, Wakabayashi H, Ogawa Y, Hibino S, et al. Efficacy of non-carbapenem antibiotics for pediatric patients with first febrile urinary tract infection due to extendedspectrum beta-lactamase-producing Escherichia coli. J Infect Chemother. 2017; 23(8):517-22.

32. Jena J, Sahoo RK, Debata NK, Subudhi E. Prevalence of TEM, SHV, and CTX-M genes of extended-spectrum $\beta$-lactamaseproducing Escherichia coli strains isolated from urinary tract infections in adults. 3 Biotech. 2017; 7(4):244.

33. Pandit R, Awal B, Shrestha SS, Joshi G, Rijal BP, Parajuli NP. Extended-Spectrum $\beta$-Lactamase (ESBL) Genotypes among Multidrug-Resistant Uropathogenic Escherichia coli Clinical Isolates from a Teaching Hospital of Nepal. Interdiscip Perspect Infect Dis. 2020; 2020:6525826.

34. Rajivgandhi G, Maruthupandy M, Manoharan N. Detection of TEM and CTX-M genes from ciprofloxacin resistant Proteus mirabilis and Escherichia coli isolated on urinary tract infections (UTIs). Microb Pathog. 2018; 121:123-30.

35. Alipour M, Jafari A. Evaluation of the Prevalence of blaSHV, blaTEM, and blaCTX Genes in Escherichia coli Isolated From Urinary Tract Infections. Avicenna J Clin Microbiol Infect. 2019; 6(3):83-7.

36. Bajpai T, Pandey M, Varma M, Bhatambare GS. Prevalence of TEM, SHV, and CTX-M Beta-Lactamase genes in the urinary isolates of a tertiary care hospital. Avicenna J Med. 2017; 7(1):12-6. 37. Ahrabi S, Derakhshanpour Khamene J. Checking the Plentitude of (BLA-SHV) B-lactamase Gene in Separated E. Colis in Children under 6 Years-Old Infected with Urinary Tract 
Hafiz et al.

Infection Referring to Tehran Central Pathobiology Laboratory (2014). Eur Online J Nat Soc Sci. 2017; 6(3):351-67. 